\title{
LUARAN PEMBERIAN KLOMIFEN SITRAT BERUPA ANGKA KEBERHASILAN KEHAMILAN PADA WANITA SINDROM OVARIUM POLIKISTIK
}

\author{
${ }^{1}$ Irwan Syah \\ ${ }^{2}$ Maria Loho \\ ${ }^{3}$ Freddt Wagey
${ }^{1}$ Kandidat Skripsi Fakultas Kedokteran Universitas Sam Ratulangi Manado
${ }^{2}$ Bagian Obstetri dan Ginekologi Fakultas Kedokteran Universitas Sam Ratulangi Manado
Email: wawansyh@gmail.com

\begin{abstract}
Polycystic ovary syndrome is the most common endocrinopathy in woman of reproductive age with an incidence that causes infertility. Woman who want to have children recomended to use ovulation induction is clomiphene citrate. Expected with the use of clomiphene citrate as first choice therapy has significcant numbers so that the use of drugs is always preffered. Purpose of this research to determine the number of pregnancies in patient with polycystic ovary syndrome with clomiphene citrate. Method used a retrospective descriptive, data of patient who treatment polycystic ovary syndrome in Prof. Dr. R. D. Kandou General Hospital Manado and practice clinical doctor conducted in the form medical therapy with clomiphene citrate. Polycystic ovary syndorme found 35 cases in the year 20122014 with 2 cases in Prof. Dr. R. D. Kandou General Hospital Manado and 33 cases in practice clinical doctor. Conceive with clomiphene citrate therapy were 9 people. Available data show clomiphene citrate still as the first choice drug for ovulation induction of polycystic ovary syndrome.
\end{abstract}

Keywords: polycystic ovary syndrome, clomiphene citrate, succsesful, pregnancy

\begin{abstract}
Abstrak: Sindrom ovarium polikistik merupakan salah satu endokrinopati paling umum pada wanita usia reproduksi dengan angka kejadian yang menyebabkan infertilitas. Wanita yang ingin mempunyai anak direkomendasikan untuk induksi ovulasi adalah klomifen sitrat. Diharapkan dengan pemberian klomifen sitrat sebagai terapi pilihan pertama mempunyai angka bermakna sehingga penggunaan obat selalu diutamakan. Tujuan Penilitian ini untuk mengetahui jumlah kehamilan pada penderita sindrom ovarium polikistik dengan terapi klomifen sitrat. Metode yang digunakan bersifat retrosepktif deskriptif, data penderita sindrom ovarium polikistik yang berobat di RSUP Prof. Dr. R. D. Kandou Manado dan dokter praktek klinik yang dilakukan terapi berupa klomifen sitrat. Ditemukan 35 kasus sindrom ovarium polikistik dari tahun 2012-2014 dengan 2 kasus terdapat di RSUP Prof Dr. R. D. Kandou dan 33 kasus di dokter praktek klinik. Berhasil hamil dengan terapi klomifen sitrat sebanyak 9 orang. Data yang ada menunjukan klomifen sitrat masih sebagai pilihan pertama obat induksi ovulasi bagi penderita sindrom ovarium polikistik.
\end{abstract}

Kata kunci: sindrom ovarium polikistik, klomifen sitrat, keberhasilan, kehamilan

Berdasarkan studi prevalensi yang dilakukan pada wanita sindrom ovarium polikisatik (SOPK) di Amerika dan beberapa negara Eropa angka kejadian yang dilaporkan berkisar 4,6-8,0\%. ${ }^{1}$
Prevalensi sindrom ovarium polikistik yang bervariasi dapat dijelaskan oleh perbedaan dalam metodologi, dalam kelompok usia dan etnis dari populasi sampel. Angka kejadian paling umum 5-10\% pada wanita 
usia reproduksi. ${ }^{2}$ Pada tahun 1935 , sindrom ovarium polikistik pertama kali dilaporkan dalam literatur medis modern oleh Stein dan Leventhal, dijelaskan tujuh perempuan yang menderita amenore, hirsutisme, dan pembesaran ovarium dengan beberapa kista. $^{3}$

Sindrom ovarium polikistik (SOPK) merupakan salah satu penyebab paling umum infertilitas yang berfokus pada gangguan ovarium, dikaitkan dengan gangguan reproduksi dan metabolisme. ${ }^{4}$ Pasien dengan SOPK umumnya datang di tempat pelayanan kesehatan dengan keluhan jerawat, pertumbuhan rambut yang berlebih dan berat badan. Hingga 95\% dari wanita SOPK memiliki ketidakteraturan menstruasi seperti oligomenore dan amenore, sehingga membuat SOPK salah satu penyebab paling umum infertilitas. ${ }^{4}$

Tujuan terapi pasien dengan SOPK harus berusaha untuk memperbaiki dan mencegah dampak klinis langsung dan jangka: mengurangi produksi dan kadar androgen dalam sirkulasi darah, melindungi endometrium dari efek unopossed estrogen, perubahan gaya hidup, menghindari efek hiperinsulinemia terhadap resiko penyakit diabetas melitus dan kardiovaskular, dan induksi ovulasi terhadap infertil. ${ }^{5}$ Wanita yang bermasalah dengan infertilitas, ingin mempunyai anak diberikan pemicu ovulasi, seperti klomifen sitrat, atau gonadtropin yang mengandung $\mathrm{FSH} / \mathrm{LH}$ atau $\mathrm{LH}$ saja. ${ }^{6}$ Berdasarkan konsensus Thessaloniki pengobatan lini pertama yang direkomendasikan untuk induksi ovulasi adalah dengan anti-estrogen klomifen sitrat. $^{7}$

Berdasarkan uraian di atas mengenai tinggi angka kejadian SOPK diseluruh dunia pada wanita usia reproduksi yang menyebabkan infertil. Diharapkan dengan pemberian klomifen sitrat sebagai terapi pilihan pertama mempunyai angka bermakna sehingga penggunaan klomifen sitrat selalu diutamakan.

\section{METODE PENELITIAN}

Penelitian ini bersifat retrosepktif deskriptif. Data diambil dari penderita sindrom ovarium polikistik yang berobat di RSUP Prof. Dr. R. D. Kandou Manado dan dokter praktek klinik dari tahun Januari 2012- September 2014 yang dilakukan terapi berupa klomifen sitrat. Keberhasilan terapi berupa kehamilan. Penelitian dilakukan sebulan Oktober sampai Desember 2013 di BLU RSUP Prof. Dr. R. D. Kandou dan dokter praktek klinik Manado. Variabel penelitian adalah penderita sindrom ovarium polikistik yang diterapi klomifen sitrat, umur, pekerjaan, lama pemberian terapi.

\section{HASIL PENELITIAN}

Dari data yang diperoleh di BLU RSUP Prof. Dr. R. D. Kandou dan dokter praktek klinik Manado pada bulan Oktober sampai Desember 2013 ditemukan 35 kasus sindrom ovarium polikistik, dengan insiden kasus yang berobat di RSUP Prof Dr. R. D. Kandou Manado sebanyak 2 kasus dan dokter praktek klinik 33 kasus.

Pada penelitian ini yang berhasil hamil dengan terapi klomifen sitrat sebanyak 9 orang, dan yang tidak berhasil hamil sebanyak 24 orang di dokter praktek klinik. Di RSUP Prof. Dr. R. D. Kandou tidak ada data tentang pemberian klomifen sitrat, jadi keberhasilan kehamilan tidak bisa ditentukan.

Tabel 1. Jumlah Keberhasilan Kehamilan

\begin{tabular}{ccccc}
\hline & \multicolumn{2}{c}{$\begin{array}{c}\text { RSUP Prof. } \\
\text { Dr. R. D. } \\
\text { Kandou }\end{array}$} & \multicolumn{2}{c}{$\begin{array}{c}\text { Dokter } \\
\text { Praktek } \\
\text { Klinik }\end{array}$} \\
\cline { 2 - 5 } & \multicolumn{2}{c}{ Klomifen sitrat } & \multicolumn{2}{c}{$\begin{array}{c}\text { Klomifen } \\
\text { sitrat }\end{array}$} \\
\cline { 2 - 5 } & $\mathrm{n}$ & $\%$ & $\mathrm{n}$ & $\%$ \\
\hline $\begin{array}{c}\text { Berhasil } \\
\text { Hamil } \\
\text { Tidak }\end{array}$ & 0 & 0 & 9 & 27 \\
$\begin{array}{c}\text { Berhasil } \\
\text { Hamil }\end{array}$ & 0 & 0 & 24 & 73 \\
\hline Total & 0 & 0 & 33 & 100 \\
\hline
\end{tabular}

Pada 17 variabel usia, pekerjaan dan lama pemberian terapi sesuai Tabel 2 didapatkan bahwa pada penderita sindrom ovarium polikistik paling banyak berada 
pada usia 25 - 29 tahun, pekerjaan ibu rumah tangga dan swasata, dan lama pemberian terapi 1 sampai 3 bulan.

Tabel 2. Karakteristik penderita

\begin{tabular}{ccccc}
\hline & $\begin{array}{c}\text { RSUP Prof. Dr. } \\
\text { R. D. } \\
\text { Kandou }\end{array}$ & \multicolumn{2}{c}{$\begin{array}{c}\text { Dokter } \\
\text { Praktek Klinik }\end{array}$} \\
\hline Usia & $\mathrm{n}$ & $\%$ & $\mathrm{~N}$ & $\%$ \\
\hline$<19$ & 0 & 0 & 0 & 0 \\
$20-24$ & 0 & 0 & 9 & 27 \\
$25-29$ & 1 & 50 & 16 & 49 \\
$30-34$ & 1 & 50 & 6 & 18 \\
$>35$ & 0 & 0 & 2 & 6 \\
\hline
\end{tabular}

\section{Pekerjaan}

\begin{tabular}{ccccc} 
IRT & 1 & 50 & 13 & 39 \\
Swasta & 1 & 50 & 7 & 22 \\
PNS & 0 & 0 & 13 & 39 \\
Mahasiswa & 0 & 0 & 0 & 0 \\
\hline $\begin{array}{c}\text { Lama } \\
\text { Pemberian } \\
\text { Terapi } \\
\text { 1-3 Bulan }\end{array}$ & 0 & 0 & 25 & 76 \\
$\begin{array}{c}\text { 4-6 Bulan } \\
>6 \text { Bulan }\end{array}$ & 0 & 0 & 7 & 21 \\
\hline Total & $\mathbf{2}$ & $\mathbf{1 0 0}$ & $\mathbf{3 3}$ & $\mathbf{1 0 0}$ \\
\hline
\end{tabular}

Pada penelitian ini dari 35 penderita sindrom ovarium polikistik yang diteliti berdasarkan umur pasien yang berhasil hamil dengan terapi klomifen sitrat di RSUP Prof Dr. R. D. Kandou Manado tidak ada, sedangkan di tempat dokter praktek klinik sebanyak 9 orang. Paling banyak di temukan pada kelompok usia 20-24 tahun sebanyak 6 orang (Tabel 3).

Pada Tabel 4 dapat dilihat bahwa dari kasus sindrom ovarium polikistik yang diteliti berdasarkan pekerjaan yang berhasil hamil dengan terapi klomifen sitrat tetap 9 orang di dokter praktek klinik, terbanyak dengan pekerjaan ibu rumah tangga.

Tabel 3. Hamil berdasarkan Usia

\begin{tabular}{ccccc}
\hline \multirow{2}{*}{ Usia } & \multicolumn{2}{c}{$\begin{array}{c}\text { RSUP Prof. } \\
\text { Dr. R. D. } \\
\text { Kandou }\end{array}$} & \multicolumn{2}{c}{$\begin{array}{c}\text { Dokter Praktek } \\
\text { Klinik }\end{array}$} \\
\cline { 2 - 5 } & \multicolumn{2}{c}{$\begin{array}{c}\text { Klomifen } \\
\text { sitrat }\end{array}$} & \multicolumn{2}{c}{ Klomifen sitrat } \\
\cline { 2 - 5 } & $\mathrm{n}$ & $\%$ & $\mathrm{n}$ & $\%$ \\
\hline$<19$ & 0 & 0 & 0 & 0 \\
$20-24$ & 0 & 0 & 6 & 66 \\
$25-29$ & 0 & 0 & 2 & 23 \\
$30-34$ & 0 & 0 & 0 & 0 \\
$\geq 35$ & 0 & 0 & 1 & 11 \\
\hline Total & 0 & 0 & 9 & 100 \\
\hline
\end{tabular}

Tabel 4. Hamil berdasarkan Pekerjaan

\begin{tabular}{ccccc}
\hline \multirow{2}{*}{ Pekerjaan } & \multicolumn{2}{c}{$\begin{array}{c}\text { RSUP Prof. } \\
\text { Dr. R. D. } \\
\text { Kandou }\end{array}$} & \multicolumn{2}{c}{$\begin{array}{c}\text { Dokter } \\
\text { Praktek } \\
\text { Klinik }\end{array}$} \\
\cline { 2 - 5 } & \multicolumn{2}{c}{$\begin{array}{c}\text { Klomifen } \\
\text { sitrat }\end{array}$} & \multicolumn{2}{c}{$\begin{array}{c}\text { Klomifen } \\
\text { sitrat }\end{array}$} \\
\cline { 2 - 5 } & $\mathrm{n}$ & $\%$ & $\mathrm{n}$ & $\%$ \\
\hline IRT & 0 & 0 & 4 & 44,45 \\
Swasta & 0 & 0 & 2 & 22,22 \\
PNS & 0 & 0 & 3 & 33,33 \\
Mahasiswa & 0 & 0 & 0 & 0 \\
\hline Total & 0 & 0 & 9 & 100 \\
\hline
\end{tabular}

Dari tabel 5 diatas dapat dilihat bahwa dari kasus sindrom ovarium polikistik yang diteliti berdasarkan lama pemberian terapi, yang berhasil hamil dengan terapi klomifen sitrat di RSUP Prof Dr. R. D. Kandou Manado tidak ada, sedangkan yang berhasil diterapi klomifen sitrat di dokter praktek klinik ditemukan sebanyak 9 orang. Paling banyak ditemukan lama pemberian terapi 1 sampai 3 bulan. 
Tabel 5. Hamil berdasarkan Lama Pemberian Terapi

\begin{tabular}{|c|c|c|c|c|}
\hline \multirow{3}{*}{$\begin{array}{c}\text { Lama } \\
\text { Pemberian } \\
\text { Terapi }\end{array}$} & \multirow{2}{*}{\multicolumn{2}{|c|}{$\begin{array}{c}\text { RSUP Prof. } \\
\text { Dr. R. D. } \\
\text { Kandou } \\
\text { Klomifen } \\
\text { sitrat } \\
\end{array}$}} & \multicolumn{2}{|c|}{$\begin{array}{c}\text { Dokter Praktek } \\
\text { Klinik }\end{array}$} \\
\hline & & & \multicolumn{2}{|c|}{ Klomifen sitrat } \\
\hline & $\mathrm{n}$ & $\%$ & $\mathrm{n}$ & $\%$ \\
\hline 1-3 Bulan & 0 & 0 & 5 & 55,56 \\
\hline 4-6 Bulan & 0 & 0 & 3 & 33,33 \\
\hline$>6$ Bulan & 0 & 0 & 1 & 11,11 \\
\hline Total & 0 & 0 & 9 & 100 \\
\hline
\end{tabular}

\section{BAHASAN}

Dari Tabel 1 di atas ditemukan bahwa jumlah penderita yang berhasil hamil dengan klomifen sitrat 9 orang(27\%) dan tidak berhasil hamil 24 orang (73\%). Ditahun 1961, Greenblatt melaporkan klomifen sitrat efektif untuk induksi ovulasi dan obat ini diresmikan oleh Food and Drug Administration (FDA) ditahun 1967. ${ }^{8}$ Konsesus Thessaloniki tahun 2008 menyatakan klomifen sitrat mempunyai angka keberhasilan kehamilan sebesar 22\% di setiap siklusnya. ${ }^{7}$ Penelitian di India tahun 2010 dengan 911 penderita SOPK yang diterapi klomifen sitrat menunjukan tingkat keberhasilan kehamilan 22\% setiap siklusnya. ${ }^{9}$ Ini menunujukan pada data yang ada klomifen sitrat mendukung teori yang disebutkan.

Kasus paling banyak berdasarkan usia setelah didiagnosis sindrom ovarium polikistik terdapat 1 kasus di RSUP Prof Dr. R. D. Kandou dan 16 kasus di dokter praktek klinik. Jadi, terdapat 17 kasus pada umur 25-29 tahun. Dari beberapa penelitian yang telah dilakukan, sindrom ovarium polikistik terjadi pada 5-10\% pada wanita usia reproduksi. 2 Dan juga prevalensi sindrom ovarium polikistik di angka 4\%$12 \%$ pada wanita usia reproduktif. ${ }^{8}$ Studi yang dilakukan 277 wanita kulit hitam dan putih di Amerika Serikat bagian tenggara terdapat $4,6 \%$ Sindrom Ovarium Polikistik. ${ }^{10}$ Penelitian di Salvador, Brazil tahun 2012 dari 853 orang kemudian terdiagnosis 73 orang SOPK rata-rata yang terkena rentang umur $28.4 \pm 6.5$ tahun. ${ }^{1}$ Studi yang dilakukan di China tahun 2010 pada wanita usia reproduktif 19-45 tahun dengan 853 penderita SOPK rata-rata berumur $29.1 \pm 5.4$ tahun. $^{11}$ Studi juga dilakukan di Korea dari 700 penderita SOPK rata-rata berumur $27.4 \pm 5.5$ tahun dan $28.6 \pm 5.1$ tahun. ${ }^{12}$ Hal ini berarti pada tabel 2 mendekati rentang usia rata-rata penderita sindrom ovarium polikistik.

Pada hasil penelitian ditemukan bahwa jumlah penderita Sindrom Ovarium Polikisitik yang berhasil hamil ditemukan 9 orang, pada tabel 3 hamil berdasarkan usia. Pada kelompok umur 20-24 tahun ditemukan sebanyak 6 orang, pada kelompok umur 25-29 tahun ditemukan sebanyak 2 orang dan pada kelompok umur $\geq 35$ tahun sebanyak 1 orang yang ditemukan. Penelitian ini sesuai dengan kepustakaan yang menyebutkan bahwa kesempatan hamil seorang wanita sampai pada usia 35 tahun sebesar $90 \%$ dan pada usia 41-45 tahun menurun 15\%.

Pada tabel 4 diatas dapat dilihat bahwa dari 35 penderita sindrom ovarium polikistik yang diteliti berdasarkan pekerjaan, yang berhasil hamil dengan terapi klomifen sitrat ditemukan 9 orang. Profesi sebagai IRT (Ibu Rumah Tangga) ditemukan sebanyak 4 orang, sebagai Swasta ditemukan sebanyak 2 orang, dan sebagai PNS ( Pegawai Negeri Sipil) sebanyak 3 orang..

Tingkat kehamilan kumulatif dengan pengobatan klomifen sitrat adalah $50 \%$ setelah 3 siklus ovulasi induksi atau 3 bulan, dan bisa sampai 75\% dalam 6-9 siklus pengobatan. ${ }^{5}$ Pada penelitian di India, setelah 3 siklus diobati terdapat angka bermakna yang berhasil hamil. ${ }^{9}$ Dalam penelitian ini ditemukan sebanyak 5 orang dengan lama pemberian terapi 1-3 bulan atau siklus yang menjadi hamil dengan terapi klomifen sitrat.

\section{SIMPULAN}

Pada penelitian ini dapat disimpulkan dari data yang ada menunjukan terdapat 
angka kehamilan setelah diterapi klomifen sitrat. Berarti Klomifen sitrat masih sebagai pilihan pertama obat induksi ovulasi pada infertilitas atau yang ingin mempunyai anak bagi penderita sindrom ovarium polikistik.

\section{SARAN}

1. Penderita yang memiliki gejala-gejala yang mirip dengan gejala Sindrom Ovarium Polikistik sebaiknya memeriksakan diri ke poliklinik Obstetri-Ginekologi atau Endokrinologi.

2. Penderita dengan diagnosis sindrom ovarium polikistik yang ingin hamil harus berkonsultasi secara berulang ke dokter spesialis Obstetri - Ginekologi direkomendasikan dengan terapi pilihan utama klomifen sitrat.

3. Perlu direkapkan kembali data di BLU RSUP Prof Dr. R. D. Kandou karena tidak semuanya valid, akhirnya penilitian yang dilakukan dengan data dalam jangka waktu 2 tahun hanya sedikit.

\section{UCAPAN TERIMA KASIH}

Penulis mengucapkan terima kasih yang sebesar-besarnya kepada semua pihak yang telah membantu penulisan artikel ini, terutama dosen pembimbing, keluarga dan sahabat-sahabat.

\section{DAFTAR PUSTAKA}

1. Gabrielli L, Aquino EML. Polycystic ovary syndrome in Salvador, Brazil: a prevalence study in primary healthcare. Reproductive biology and endocrinology. 2012;10(96)

2. Ott J, Kurz C, Nouri $K$, Wirth $S$, Binstorfer EV, Huber JC, et al. Pregnancy Outcome in Women with Polycystic Ovary Syndrome Comparing the Effects of Laparoscopic Ovarian Drilling and Clomiphene Citrate Stimulation in Women pre-Treated with Metformin: A Retrospective Study. Reproductive biology and endocrinology. 2010;8(45)

3. Sirmans SM, Pate KA. Epidemiology, diagnosis, and Management of Polycystic Syndrome. Clinical epidemiology. 2014;6;1-13.

4. Berger JJ, Bates GW. Optimal management of subfertility in polycystic ovary syndrome. International journal of women's health. 2014;6:613-21.

5. Fritz MA, Speroff L. Clinical Gynecologic Endocrinology and Infertility. $8^{\text {th }}$ ed. Philladelphia : Lippincott Williams \& Wilkins, a Wolters Kluwer buisness; 2011:495531.

6. Hasim HA. Management of Women with Clomiphene Citrate Resistant Polycystic Ovary Syndrome An Evidence Based Approach. In: Srabani Mukherjee. Polycystic Ovary Syndrom: Intech; 2012.1-2.

7. The Thessaloniki ESHRE/ASRM Sponsored PCOS Consensus Workshop Group. Consensus on Infertility Treatment Related to Polycystic Ovary Syndrom. Fertility and Sterility. 2008;89(3);505.

8. Chang RJ. Polycystic Ovary Syndrome and Hyperandrogenis States. In: Strauss JF, Barbieri RL. Yen and Jaffe's Reproductive Endocrinology: Physiology, Pathophysiology, and Clinical Managemant. $6^{\text {th }}$ ed.China: Saunders Elsevier; 2009:508-10

9. Mukherjee S, Sharma S, Chakravarty BN. Comparative evaluation of pregnancy outcome in gonadotrophinclomiphene combination vs clomiphene alone in polycystic ovarian syndrome and unexplained infertility-A prospective clinical trial. Journal of Human Reproductive Sciences. 2010;3(2);80-84.

10. Azziz R. Definition, Diagnosis, and Epidemiology of the Polycystic Ovary Syndrome. The Polycystic Ovary Syndrome: Current Concepts On Pathogenesis And Clinical Care. 2011;1;1-15..

11. Li R, Yu G, Yang D, Li S, Lu S, Wu X, et al. Prevelance and Predictors of Metabolic Abnormalities In Chinese women with PCOS : a cross sectional study.BMC Endocrine Disorders. 2014;14(76)

12. Kim MJ, Lim NK, Choi YM, Kim JJ, Hwang KR, Chae SJ, et al. 
Syah, Loho, Wagey: Luaran pemberian klomifen...

Prevelance of Metabolic Syndrome is Higher among Non-Obese PCOS Woman with Hyperandrogenism and

Menstural Irregularity in Korea. Metabolic Syndrome and Polycystic Ovary Syndrome. 2014;9(6) 